\title{
Correction to: Evaluation of convective parameters derived from pressure level and native ERA5 data and different resolution WRF climate simulations over Central Europe
}

\author{
Ákos János Varga' ${ }^{1}$ [ Hajnalka Breuer ${ }^{1}$ (D)
}

Published online: 25 October 2021

(c) The Author(s) 2021

\section{Correction to: Climate Dynamics}

https://doi.org/10.1007/s00382-021-05979-3

In the original version of the article, the column labels in Figure 3 were incomplete.

The original article has been corrected.

The original article can be found online at https://doi.org/10.1007/ s00382-021-05979-3.

Ákos János Varga

vakos94@staff.elte.hu

1 Department of Meteorology, Institute of Geography and Earth Sciences, ELTE Eötvös Loránd University, Pázmány Péter sétány 1/A, Budapest 1117, Hungary 


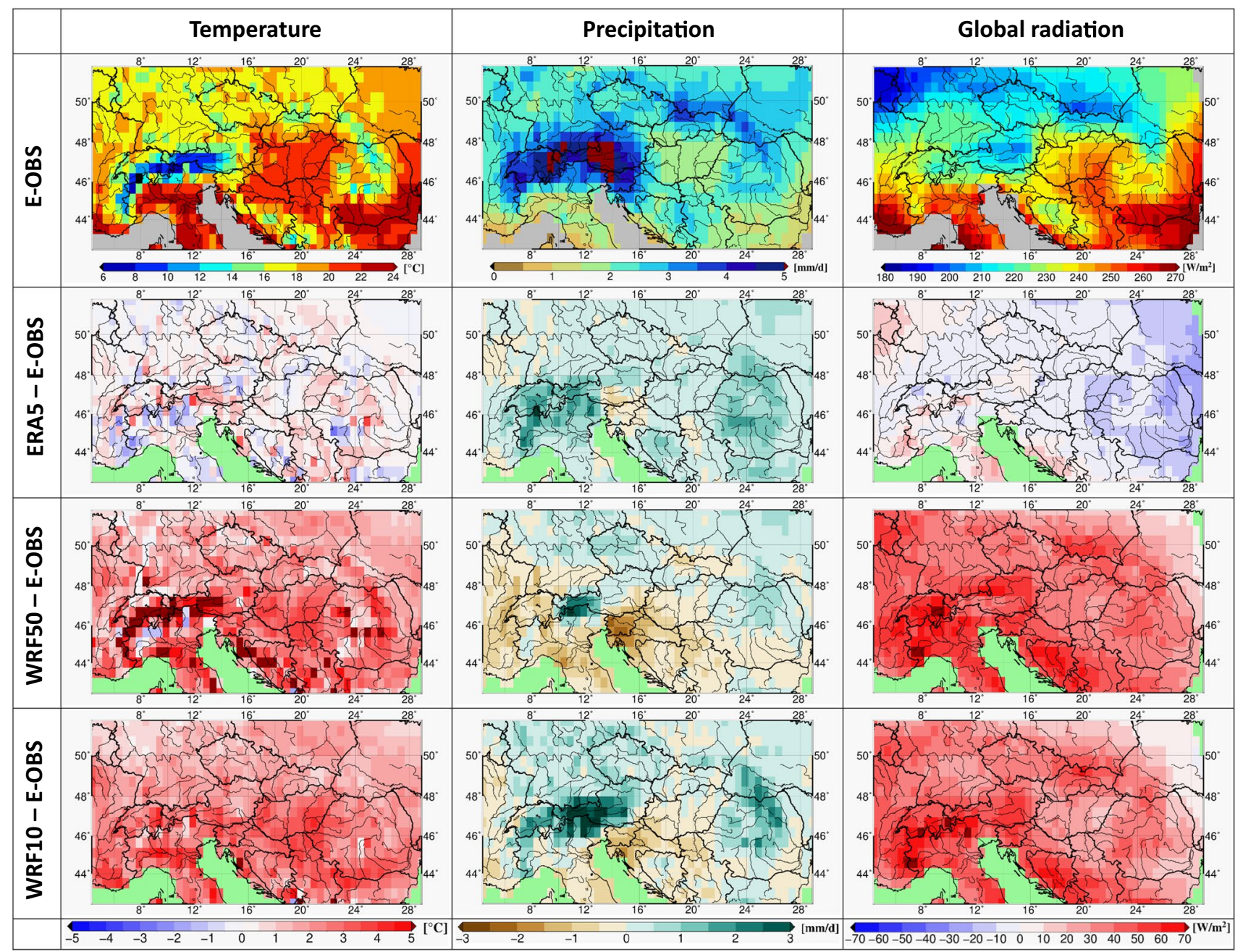

Fig. 3 Mean summer (JJA) temperature, precipitation, and global radiation from E-OBS and biases of ERA5, WRF50, and WRF10 in the 19852010 period

Publisher's Note Springer Nature remains neutral with regard to jurisdictional claims in published maps and institutional affiliations. 